Original Research

\title{
Family-Based Maternal Sensitivity Model as a Strategy to Optimize Family Perception on the Role of Parents and the Growth of Infants
}

\author{
Diyan Indriyani and Susi Wahyuning Asih \\ Faculty of Health Sciences, University of Muhammadiyah Jember, Jember, Indonesia
}

\begin{abstract}
Introduction: Family perceptions on the role of parents and the growth of infants must be seriously considered by healthcare workers since they can affect the role of family development in taking care of the babies. A family that has optimally understood the role of their development as a parent will be able to give the appropriate care for the babies.

Methods: The study aimed to find out the effects of a family-based Maternal Sensitivity Models (MSM) strategy for family perception optimization on the role of parents and the growth of infants. It used a quasi-experimental design with the samples of 50 families. The samples were obtained using purposive sampling technique. The data were analyzed using dependent t-test.

Results: It confirmed that the Family-Based Maternal Sensitivity Models (MSM) strategy significantly affects family perceptions on the role of parents with t-value 5.915 and p-value 0.000. MSM also significantly affects family perceptions on the growth infants with the t-value -11.257 and $\mathrm{p}$-value 0.000 .

Conclusion: Maternal Sensitivity Models (MSM) can be well applied as one of the health models provided by healthcare workers to optimize parents' perceptions and infants' growth as well as to develop a competent family in giving care for their babies.
\end{abstract}

\section{ARTICLE HISTORY}

Received: August 27, 2017

Accepted: April 18, 2018

\section{KEYWORDS}

maternal sensitivity model; family perceptions; role of parents; growth of infants

\section{CONTACT}

Diyan Indriyani

$\triangle$ diyanindriyani@unmuhjember.ac.id $\equiv$ Faculty of Health Sciences, University of Muhammadiyah Jember, Jl. Karimata 49 Jember, East Java, Indonesia

Cite this as: Indriyani, D., \& Asih, S. (2018). Family-Based Maternal Sensitivity Model as a Strategy to Optimize Family Perception on the Role of Parents and the Growth of Infants. Jurnal Ners, 13(1), 18-23. doi:http://dx.doi.org/10.20473/in.v13i1.5690

\section{INTRODUCTION}

The birth of a baby is a process that can change the life of the family. The presence of a new family member makes the family, especially parents, have new roles, duties and responsibilities. The process is a transitional period that can provide both physical and psychological impacts on the developmental stage of the family (Wright and Leahey, 2009).The transitional period of this stage becomes the trigger factor of stress and imbalance in the family if they are not able to play their new roles as parents (Friedman, Bowden and Jones, 2010). Every family has roles related to the responsibilities which must be accomplished in order to fulfill the needs of the family.

The role of the family related to the baby is to provide infant care and to monitor infant growth
(Kaakinen et al., 2015). The family has an important role to support the parents in caring for their baby. However, most parents are less skilled in caring for babies, including how to monitor their growth and development. This is consistent with the 2004 Infant Health and Development (IHDP) survey which found that parents are low-skilled in caring for their babies. Such condition is caused by many factors, such as the dominance of the role of grandmother, grandfather and other family members (Indriyani, Asmuji and Wahyuni, 2016). This phenomenon often occurs in most families in Indonesia because it relates to the culture adopted by each family (Asmuji and Indriyani, 2014). The research (Asmuji and Indriyani, 2014) recommends the importance of policy makers in formulating programs related to the empowerment of families in optimizing their parenthood role. 
One of the efforts which can solve those problems is by improving the ability of families regarding a parent's role and the ability to monitor the growth of infants. Maternal Sensitivity Models (MSM), developed by the researcher, can be performed to conduct those efforts by involving the family as social support. This model shows its advantages when the family perception increases and the family is actively involved in the efforts, in which the function of infant care will be better and more appropriate (Dokken and Ahmann, 2006). The increase will lead the family to work actively and to have expertise in providing support to the infant's parents and monitoring infant growth. It will also contribute to the optimization of the health status of infants, which is actually the mother's responsibility. The involvement of the family in caring for the infant is expected to reduce infant mortality rate.

The present research is similar to the research conducted by Mendelson et al. (2013) which showed that infant-based psychological intervention could prevent postpartum depression and affect social support. However, the previous research only involved mother and baby in preventing postpartum depression while family involvement has not been performed optimally. Another similar research suggests that a continuing education program through public health nurses is important to be provided to the family, with limitation only for the families who have babies with very low birth weight (Pridham et al., 2006). Based on the background, the development of Maternal Sensitivity Models (MSM) is important to make the interventions more complete by involving the family to improve their competence in carrying out the role of parents and monitoring infant growth (Pontoppidan, 2015).

Therefore, the aim of this study was to analyze the effects of Maternal Sensitivity Models (MSM) in regards to the optimization of family perceptions on parents' role and infant growth.

\section{MATERIALS AND METHODS}

The study used quantitative research with quasiexperiment design and aimed to analyze the effectiveness of Maternal Sensitivity Models (MSM) that have been formulated to optimize the family perception of parents' role and infant growth. The study was conducted in March-June 2017 in Sumbersari and Sukorambi Districts, Jember, East Java, Indonesia.

The data collection was started by measuring the family's perceptions on parents' role and infant growth (pre-test) using questionnaires. After the pretest, the researchers performed the implementation of Maternal Sensitivity Models (MSM) which focused on training and education about parents' role and stimulation of infant growth. It was implemented for three months with six interventions. The last stage was to evaluate the changes in family perceptions related to parents' role and infant growth (post-test).
The variables consisted of Maternal Sensitivity Models (MSM) as independent variable and family perceptions of parents' role and family perceptions on infant growth as dependent variables. The population of the study was families who have babies aged 1-12 months. The sample was 50 families taken using purposive sampling with inclusions and exclusions criteria. The inclusion criteria were families who have babies and babies living at home with parents. Meanwhile, the exclusion criteria were the baby being sick during the intervention and the husband was not at home. The instrument used was a questionnaires distribution about family perceptions on the optimization of parents' role and infant growth developed by researcher. The scoring system of the instrument used numerical data from a score of 20100 with parameters measured being cognitive, affective and conative components. The reliability value of the questionnaire perceptions on the role of parents used Cronbach's Alpha of 0.79 and reliability questionnaire perceptions on the growth infants of 0.81 . The data analysis used dependent t-test with $\alpha$ (alpha) value of $5 \%(0.05)$.

The study has passed ethical clearance with Number 003/KEPK/FIKES/III/2017 issued by the Health Research Ethics Committee, Faculty of Health Sciences, University of Muhammadiyah Jember on March 4, 2017. Thus, the implementation of research has also applied the principle of non-maleficence ethic where the researchers agree the time of implementation of the intervention with the families. Another ethical principle is beneficence, by applying research benefits to respondents by explaining them the benefits of intervention. Another ethical principle is also respect of human dignity by means of the researchers affording freedom to the families in thinking and deciding consciously and without applying pressure or coercion to take part or refusing participation in the present research, conducted by using informed consent. Furthermore, the familybased Maternal Sensitivity Models (MSM) approach can be seen in the figure 1 .

\section{RESULTS}

Table 1 shows that the greatest number of age of family is 20-35 years old with 29 respondents (58\%). The greatest number of the family profession is labor and trader with 18 respondents (36\%). Table 1 also shows that the greatest number of family education background is senior high school with 32 respondents (64\%).

Table 2 shows that family-based Maternal Sensitivity Models (MSM) application significantly affects family perceptions on the role of the family in infant care with p-value 0.000 .

Based on the table 3, it can be seen that familybased Maternal Sensitivity Models (MSM) application also significantly effects the family perceptions on infant growth with p-value 0.000 . 


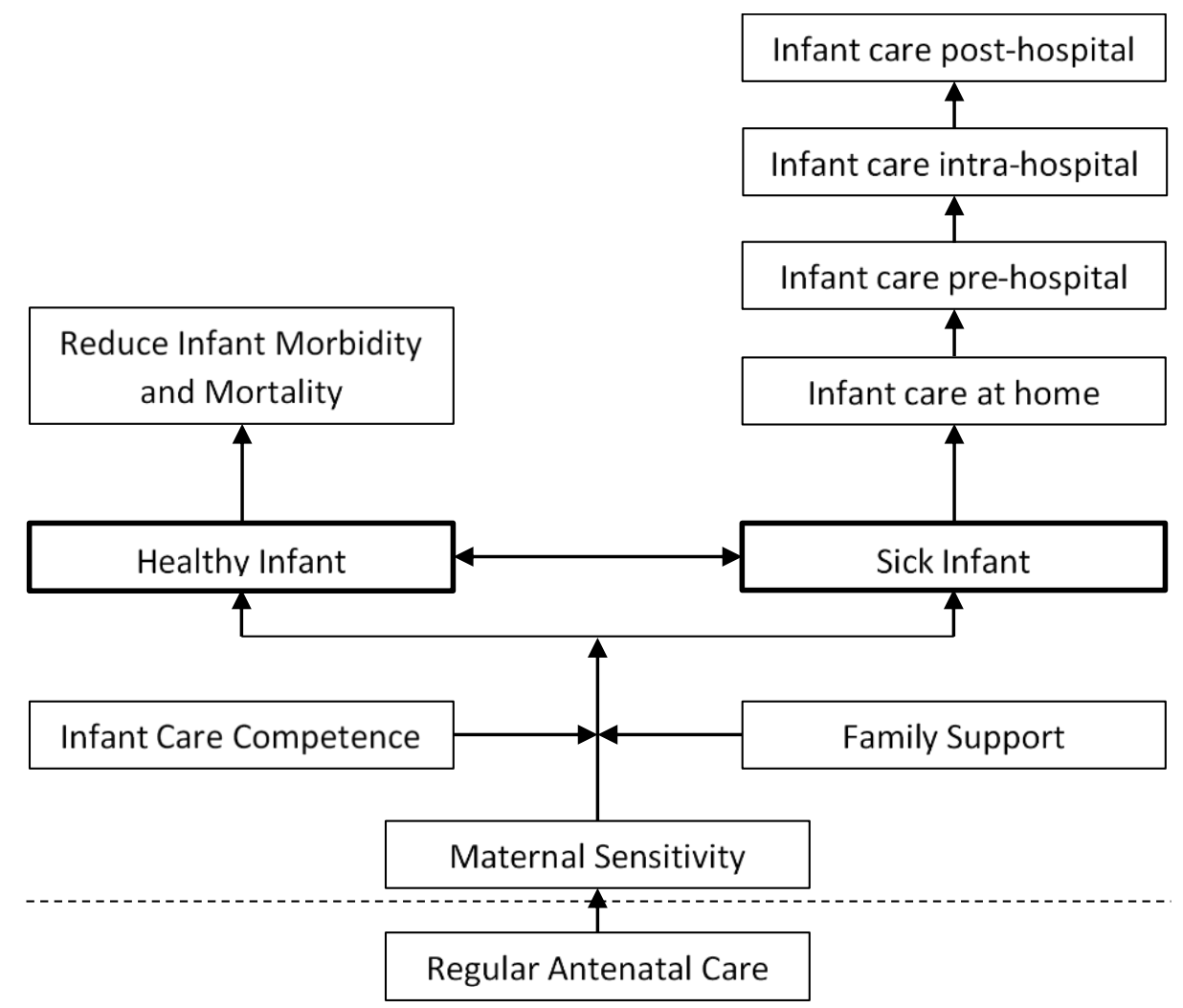

Figure 1. Family-Based Maternal Sensitivity Model in Optimization of Infant Care Competence

\section{DISCUSSION}

The family-based Maternal Sensitivity Models (MSM) have a significant effect on family perceptions on parents' role in infant care. The family-based Maternal Sensitivity Models (MSM) approach in improving family perceptions on parent's role is in accordance with nursing intervention step in Nursing Intervention Classification (NICs): designing educational programs based on family strength, identifying personal factors that impact on the success of the program (e.g., cultural values, negative experiences, time commitments, interests), facilitating family discussions on parenting methods, teaching the families about physiological, emotional and infant care, and helping the families to identify evaluation criteria for daily infant care.

The concept is supported by the results of triple parenting program interventions that shows that infant care programs which are supported by family involvement are proven to be effective in increasing family satisfaction in carrying out the role of parenting (McConnell, Breitkreuz and Savage, 2012; Williams and Hutchings, 2015). Maternal Sensitivity Models (MSM) interventions that make families as social support for other family members has formed a continuous interaction among family members in performing their roles, so that these conditions can effectively improve communication and harmony within the family. Social support of the family (physical, emotional and instrumental supports) in a parenting role has formed cognitive and affective awareness of the family members so as to perform their role (Padden et al., 2013; Pender, Murdaugh and Parsons, 2015). It is also in accordance with the results of the research conducted by Pontoppidan (2015) suggesting that family involvement programs in infant care are effective to overcome the physical and psychological problems of infants. Family involvement programs in infant care also support the success of breastfeeding (Langlois and Smith-Sharp, 2001; Nuzulia, 2011; Daniels et al., 2015; Swigart et al., 2017).

Instrumental support (such as assisting infant care, complementary roles and tasks in fulfilling the role of infant care), emotional support (such as praise, loving relationship), and information support (such as ideas and suggestions) are the key support that contributes to the role of family care. Therefore, family support is very important for families who have babies (Hamilton, 2010) . This is consistent with the research (Verhage, Oosterman and Schuengel, 2015) suggesting that family support affects the parents' role in parenting, so that it affects the baby's temperament as well. In contrast, a research conducted by Hegedus and Mullan (2015) shows that, in Australia, which is a developed country, the family support for baby care in supporting the breastfeeding process has not yet been performed optimally.

Family support is a key point in Maternal Sensitivity Models (MSM) so that family perceptions of the parent role can be increased. The family is the main social support for the developmental stage of 
Table 1. Frequency Distribution of the Age, the Profession and Education Background of Families $(n=50)$

\begin{tabular}{cccc}
\hline Demographic Data & & Number & Percentage \\
\hline Age & $<20$ years old & 7 & 14.0 \\
& $20-35$ years old & 29 & 58.0 \\
& $>35$ years old & 14 & 28.0 \\
& Total & 50 & 100.0 \\
\hline Profession & Labor and Trader & 18 & 36.0 \\
& Farmer & 11 & 22.0 \\
& Civil Servants & 9 & 18.0 \\
& Self-employed & 12 & 24.0 \\
& Total & 50 & 100.0 \\
\hline Education Background & Junior High School & 14 & 28.0 \\
& Senior High School & 32 & 64.0 \\
& Higher Education & 4 & 8.0 \\
& Total & 50 & 100.0 \\
\hline
\end{tabular}

Table 2. The Effects of Family-based Maternal Sensitivity Models (MSM) to Family Perceptions on Parents' Role $(\mathrm{n}=50)$

\begin{tabular}{ccccc}
\hline Variable & Mean & Std. Deviation & Std. Error Mean & p-Value \\
\hline $\begin{array}{cccc}\text { Perceptions of the Role of Parents in Infant Care } \\
\text { Pre-test }\end{array}$ & & & \\
Post-test & 71.00 & 7.626 & 1.079 & 0.00 \\
\hline
\end{tabular}

Table 3 The Effects of Family-based Maternal Sensitivity Models (MSM) to Family Perceptions on Infant Growth $(\mathrm{n}=50)$

\begin{tabular}{ccccc}
\hline Variable & Mean & Std. Deviation & Std. Error Mean & p-Value \\
\hline Perceptions on infant growth & & & & \\
\hline Pre-test & 60.60 & 7.117 & 1.007 & 0.00 \\
Post-test & 76.40 & 6.627 & 0.937 & \\
\hline
\end{tabular}

the family with babies because there is a transition period into a new family at this stage that requires optimal support from other family members (Kaakinen et al., 2015).

The parents' role in undertaking infant care is very important because it affects the physical and mental conditions of the baby (Dokken and Ahmann, 2006; Day, Bernheimer and Weisner, 2007). The previous research shows that poor baby personality is associated with self-efficacy or parenting skills in infant care (Padden et al., 2013; Verhage et al., 2015).Therefore, it needs family support from other family members to optimally realize the parents' role (Hickey et al., 2016).Therefore, it needs powerful support from other family members in realizing the optimal parent role. Maternal Sensitivity Models (MSM) use family strength resources and family potential as key social support in enhancing the parental role so that MSM is proven to improve family perceptions on the parental role.

Another result of the present research also confirms that family-based Maternal Sensitivity Models (MSM) have an effect on family perceptions on infant growth. It becomes something that is rarely noticed by families who have babies. The family perceptions on infant growth can be well improved through family-based Maternal Sensitivity Models (MSM). This is because the support provided by the family becomes a stimulus that can improve the perceptions of other family members, so that there is an exchange of information from each family member. Also, it indicates that support given to families who have babies from other family members can improve the health status of the babies, one such is related to infant growth (Adema, Clarke and Frey, 2016).

The families who get full support from family members get many benefits for both the family and the baby. The family which supports the young mother in monitoring the growth of babies, e.g., accompanying the young mother in monitoring the height and weight and monitoring the development of infants in Posyandu or in other healthcare services can create harmonious and happy conditions for families.

Programs involving family members, in infant care, are also evident by studies showing that family support greatly contributes to improving infant health and lowers stress levels while undergoing infant care (Pontoppidan, 2015).

One indicator of infant health is infant growth. It is influenced by many factors, one of which is the parent role. In accordance with the related theory, it shows that psychosocial factors are the ability of parents in stimulating the development of infants, as well as motivation in caring for babies and these can affect infant growth and development. Parents who often 
stimulate infant development will have a different impact on infant development than the parents who never give stimulation for infant growth (Hockenberry and Wilson, 2009).

Family perceptions on infant growth is important to be improved since it affects infant growth and development. Maternal Sensitivity Models (MSM) that make the family as the main social support of family perception about baby growth can be improved. This is due to the support provided by the family to other family members. This opinion is also supported by a meta-analysis study showing that nursing interventions given by involving families are more effective in improving parenting tasks, such as monitoring infant growth (Tanninen et al., 2015).

Nurses who involve families in providing interventions have the virtue of being able to see the potential of the family and exploiting the potential of the family in supporting other family members to fulfill their duties and responsibilities in providing infant care, including about infant growth, so that infant growth can be achieved optimally.

\section{CONCLUSIONS}

Family is major social support in realizing and improving infant health status. A family-based Maternal Sensitivity Models (MSM) approach as the main social support for other family members significantly affects the family perceptions on the parent role and infant growth.

\section{REFERENCES}

Adema, W., Clarke, C. and Frey, V. (2016). Paid parental leave and other supports for parents with young children: The United States in international comparison. International Social Security Review, 69(2), pp. 29-51. https://doi.org/10.1111/issr.12100

Asmuji, I.D. (2014). Model Edukasi Postnatal Melalui Pendekatan FCMC sebagai Strategi Optimalisasi Competence Mothering dalam Menurunkan Angka Kematian Ibu dan Bayi di Kabupaten Jember. Jurnal Keperawatan, 2.

Browne, J.V., Langlois, A., Ross, E.S. and Smith-Sharp, S. (2001). BEGINNINGS: an interim individualized family service plan for use in the intensive care nursery. Infants \& Young Children: An Interdisciplinary Journal of Early Childhood Intervention, 14(2), pp.19-32. [online] Available at:

http://search.ebscohost.com/login.aspx?direct=t rue \&db=cin $20 \& A N=106920225 \&$ site=ehost-live (Accessed: June 24, 2017).

Daniels, L., Heath, A.-L. M., Williams, S. M., Cameron, S. L., Fleming, E. A., Taylor, B. J., Wheeler, B.J., Gibson, R.S. and Taylor, R. W. (2015). Baby-Led Introduction to SolidS (BLISS) study: a randomised controlled trial of a baby-led approach to complementary feeding. $B M C$ Pediatrics, $15(1), \quad$ p. 179. https://doi.org/10.1186/s12887-015-0491-8
Day, A., Bernheimer, L. P. and Weisner, T. S. (2007). Let Me Just Tell You What I Do. Infants \& Young Children, 20(3), pp. 192-201.

Dokken, D. and Ahmann, E. (2006). The many roles of family members in "family-centered care" -- part I. Pediatric Nursing, 32(6), pp.562-565 [online] Available at: http://search.ebscohost.com/login.aspx?direct=t rue $\& \mathrm{db}=\mathrm{rzh} \& \mathrm{AN}=106268035 \&$ site $=$ ehost-live (Accessed:).

Friedman, M.M., Bowden, M. and Jones, K. (2010). Buku ajar keperawatan keluarga: Riset, teori, dan praktik. Jakarta: EGC.

Hamilton, K. (2010). Parental Physical Activity: Exploring the Role of Social Support. American Journal of Health Behavior, 34(5), pp. 573-84. https://doi.org/10.5993/AJHB.34.5.7

Hegedus, J. and Mullan, J. (2015). Are we adequately providing support services for optimal infant nutrition in Australia? A study in regional NSW. Australian Journal of Primary Health, 21(3), pp.293-298. https://doi.org/10.1071/PY14044

Hickey, G., McGilloway, S., Furlong, M., Leckey, Y., Bywater, T. and Donnelly, M. (2016). Understanding the implementation and effectiveness of a group-based early parenting intervention: a process evaluation protocol. $B M C$ Health Services Research, 16(1), p. 490. https://doi.org/10.1186/s12913-016-1737-3

Hockenberry, M.J. and Wilson, D. (2009). Wong's essentials of pediatric nursing. $8^{\text {th }}$ th ed. St Louis: Mosby.

Indriyani, D., Asmuji and Wahyuni, S. (2016). Edukasi Postnatal Dengan Pendekatan Family Centered Maternity Care (FCMC). Yogyakarta: Trans Medika.

Kaakinen J R, Coehlo D P, Steele R, Tobacco, A. and Hanson, S. M. (2015). Family health care nursing: Theory, practice, and research $5^{\text {th }}$ ed. Philadelphia: Davis Company.

McConnell, D., Breitkreuz, R. and Savage, A. (2012). Independent evaluation of the Triple P Positive Parenting Program in family support service settings. Child and Family Social Work, 17(1), pp. 43-54. https://doi.org/10.1111/j.13652206.2011.00771.x

Mendelson, T., Leis, J. A., Perry, D. F., Stuart, E. A. and Tandon, S. D. (2013). Impact of a preventive intervention for perinatal depression on mood regulation, social support, and coping. Archives of Women's Mental Health, 16(3), pp.211-218. https://doi.org/10.1007/s00737-013-0332-4

Nuzulia, F. (2011). Hubungan antara Dukungan Keluarga dengan Pemberian ASI Eksklusif pada Bayi di Desa Bebengan Kecamatan Boja Kabupaten Kendal, pp.1-8.

Padden, D. L., Connors, R. A., Posey, S. M., Ricciardi, R. and Agazio, J. G. (2013). Factors Influencing a Health Promoting Lifestyle in Spouses of Active Duty Military. Health Care fpr Women International, 34(8), pp. 674-693. https://doi.org/10.1080/07399332.2012.73657 2 
Pender. N, Murdaugh, C, and Parsons, M, A. (2015). Health promotion in nursing practice $7^{\text {th }}$ ed. Sidney: Appleton \& Lange.

Pontoppidan, M. (2015). The effectiveness of the Incredible Years ${ }^{\mathrm{TM}}$ Parents and Babies Program as a universal prevention intervention for parents of infants in Denmark: study protocol for a pilot randomized controlled trial. Trials, 16(1), p. 386. https://doi.org/10.1186/s13063-015-0859-y

Pridham, K. F., Limbo, R. K., Schroeder, M., Krolikowski, M. M. and Henriques, J. B. (2006). A continuing education program for hospital and public health nurses to guide families of very low birth-weight infants in caregiving. Journal of Continuing Education in Nursing, 37(2), pp. 74-85. https://doi.org/10.3928/00220124-2006020105

Swigart, T. M., Bonvecchio, A., Théodore, F. L., Zamudio-Haas, S., Villanueva-Borbolla, M. A. and Thrasher, J. F. (2017). Breastfeeding practices, beliefs, and social norms in low-resource communities in Mexico: Insights for how to improve future promotion strategies. PLOS ONE, 12(7), pp.1-22. https://doi.org/10.1371/journal.pone.0180185
Tanninen, H.-M., Häggman-Laitila, A., Pietilä, A.-M. and Kangasniemi, M. (2015). The content and effectiveness of home-based nursing interventions to promote health and well-being in families with small children: a systematic review. Scandinavian Journal of Caring Sciences, (19). https://doi.org/10.1111/scs.12251

Verhage, M. L., Oosterman, M. and Schuengel, C. (2015). The linkage between infant negative temperament and parenting self-efficacy: The role of resilience against negative performance feedback. British Journal of Developmental Psychology, 33(4), pp. 506-518. https://doi.org/10.1111/bjdp.12113

Williams, M. E. and Hutchings, J. (2015). A pilot effectiveness study of the Enhancing Parenting Skills (EPaS) 2014 programme for parents of children with behaviour problems: Study protocol for a randomised controlled trial. Trials, 16(1), pp. 1-10. https://doi.org/10.1186/s13063-0150741-y

Wright L.M. and Leahey.M. (2009). Nurses and families: A guide to family assessment and intervention. $5^{\text {th }}$ ed. Philadelphia: FA Davis Company. 